\title{
Resultados de Experiência de Ensino de Projeto de Design para Jovens em Escolas Técnicas
}

\author{
Results of an Experience of Teaching Design to Young Adults in Technical Schools
}

DINELLI, Maria Beatriz Saraiva; Mestranda no Programa de Pós-Graduação em Design; Faculdade de Arquitetura e Urbanismo da Universidade de São Paulo

beatrizdinelli@usp.br

\section{Resumo}

Este artigo objetiva refletir sobre a pedagogia de design em escolas técnicas, visando à resolução de problemas a partir de experiências práticas de ensino de projeto para jovens no Curso Técnico de Design Gráfico do Senac-SP. O projeto consistia no redesign de embalagem cartonada de produtos comercializados em supermercados e criação de materiais promocionais. Por meio de pesquisa qualitativa, observações "in loco", relatórios de pesquisa, pranchas de visualização e arquivos visuais digitais, buscou-se identificar, a partir de três projetos selecionados, abordagens distintas de soluções de design pela ótica dos próprios alunos e posterior análise formal, com base em Lupton e Phillips, e de retórica visual-verbal, segundo Bonsiepe. A dedicação às etapas de pesquisa e experimentação parece haver contribuído para melhor entendimento de problemas desta natureza, facilitando sua resolução, de uma perspectiva mais crítica, havendo estimulado, em vários alunos, maior capacidade de articulação a respeito de categorias conceituais do design.

Palavras Chave: pedagogia de design para jovens; ensino técnico de design; ensino de design gráfico.

\begin{abstract}
This article reflects on design pedagogy in technical schools, based on the problem-solving approach through the practical experience of teaching design to young adults in the Technical Course in Graphic Design at Senac-SP. The project consisted of the redesign of carton packaging of products sold in supermarkets and the creation of promotional material. Through qualitative research, in situ observations, research reports, visualization boards and digital visual files, the aim was to identify, among three selected projects, different approaches to design solutions from the students' perspective accompanied by formal analysis, based on Lupton and Phillips, and visualverbal rhetoric, according to Bonsiepe. The dedication to the stages of research and experimentation seems to have contributed to a better understanding of problems of this nature, facilitating their resolution from a more critical perspective, having stimulated, in several students, a greater articulation capacity with respect to conceptual categories of design.
\end{abstract}

Keywords: design pedagogy for young adults; design technical education; graphic design pedagogy. 


\section{Introdução}

Ao projetar, designers estão envolvidos com decisões sobre formato, cor, localização, proporção, imagens e estilos. Uma vez que a hierarquia visual procura controlar a transmissão e o impacto da mensagem, há a necessidade de se manter a legibilidade ao redor dos planos em projetos tridimensionais (LUPTON; PHILLIPS, 2015). Além disto, a construção da linguagem visual de embalagens requer conhecimentos que ultrapassam os domínios da comunicação visual, perpassando o marketing e o comportamento do consumidor (NEGRÃO; CAMARGO, 2008). Estes apontamentos, entre outros aspectos, revelam a complexidade que envolve um projeto de embalagem para um designer profissional e, mais ainda, para um jovem iniciante. Assim, este estudo se propõe a apresentar e refletir sobre a pedagogia de design para jovens em escolas técnicas, com base em uma perspectiva de resolução de problemas afetos ao design e identificar abordagens utilizadas pelos alunos nas soluções desenvolvidas, tomando como base experiências práticas de ensino de projeto para jovens no Curso Técnico de Design Gráfico no Serviço Nacional de Aprendizagem Comercial (Senac), em São Paulo, ministrado em 2015.

Para isto, foram usadas técnicas de pesquisa qualitativa, por meio de observações in loco, entrevistas com usuários, coletas de amostras e levantamentos na internet. Os dados utilizados para análise compreendiam relatórios de pesquisa (tais como: briefing, estudos de campo, justificativas, conceito, formato, identidade visual, paleta de cores, tipografia empregada), pranchas de visualização e arquivos digitais das artes finais das peças e apresentação final. O presente artigo está estruturado em duas seções: a) análise das abordagens utilizadas no processo de redesign ${ }^{1}$ de três embalagens selecionadas sob a ótica dos próprios alunos e posterior síntese; e b) análise formal das soluções de design destas embalagens a partir de Lupton e Phillips, e por meio da retórica visual-verbal, segundo Bonsiepe.

\subsection{Contexto Histórico do Ensino Técnico}

Se, historicamente, cursos técnicos são vistos como formação menor, evidenciada pela estrutura do ensino brasileiro: de um lado, a formação propedêutica responsável pela formação geral e, de outro, a formação técnica profissional, correspondendo à formação específica (FERRETTI, 2006), a ênfase na prática é um diferencial do ensino técnico, que, por meio da utilização de laboratórios de ensino, podem proporcionar aos estudantes maior interação com a teoria (SCACCHETTI, 2013). Bonsiepe $(2015$, p. 171) também alerta para a necessidade de se buscar equilíbrio entre teoria e prática no ensino, uma vez que: "Um ensino orientado somente à prática não acerta a prática".

Em contraste à reestruturação produtiva dos anos 1980, que exigiu formação mais sofisticada do técnico, com aproximação da formação geral à formação específica, e a teoria da prática (FERRETTI, 2006), nos anos 1990, o modelo de competência² surgiu para orientar a formação de recursos humanos compatível com a organização do trabalho, com ênfase menos na posse dos saberes técnicos e mais em sua mobilização para enfrentar imprevistos e solucionar problemas, o que refletiu na configuração do currículo do ensino técnico atual (FERRETTI, 1997).

\footnotetext{
${ }^{1}$ Redesign: atividade de reprojeto buscando aperfeiçoar aspectos considerados inadequadamente resolvidos em dado produto já existente, seja no âmbito estrutural, informacional, material, de processos produtivos ou outro.

2 "Competência designa saber ser, mais do que saber fazer e implica dizer que o trabalhador competente é aquele que sabe utilizar todos os seus conhecimentos - obtidos através de vários meios e recursos - nas mais diversas situações encontradas em seu posto de trabalho." (DESAULNIERS, 1993, p. 100).
} 
Segundo relatório do Banco Mundial de 2015, o Brasil vem apresentando avanços no ensino técnico e profissional, em especial na ampliação de seu acesso e na qualidade. Cabe, entretanto, verificar a relevância e atualização dos currículos para a formação pretendida, bem como a existência de adequação na pedagogia em função das propostas (COSTIN, 2015).

\subsection{Ensino Técnico no Senac}

Em 1946, no início das atividades do Senac, a organização dos currículos da educação profissional objetivava preparar mão-de-obra especializada, de níveis técnico-administrativo médio e básico, para atender às demandas do desenvolvimento industrial e comercial do país. A partir do estabelecimento das Diretrizes Curriculares Nacionais para os Cursos Técnicos (BRASIL, 1999), percebeu-se maior valorização e investimento na divulgação da Educação Profissional Técnica de Nível Médio.

O Senac se propõe a práticas pedagógicas que estimulem o aluno a construir o conhecimento e a desenvolver competências. Metodologias estruturadas na prática, baseadas em situações reais de trabalho, por meio de estudos de caso, pesquisas, solução de problemas, projetos e outras estratégias apoiadas em recursos da tecnologia educacional. Os currículos são definidos em Planos de Curso de Educação Profissional, atendendo à legislação, diretrizes e regulamentações específicas, sejam as nacionais, instituídas pelo Conselho Nacional de Educação e órgãos do Ministério da Educação, sejam as complementares, do Conselho Estadual de Educação, quando se tratar de Curso Técnico de Nível Médio.

\subsection{Curso Técnico de Design Gráfico no Senac São Paulo}

O Curso Técnico de Design Gráfico ofertado no Senac São Paulo, denominado Técnico em Comunicação Visual, é estruturado em cinco módulos. As situações de aprendizagem previstas para cada módulo têm como eixo condutor um projeto que considera contextos similares àqueles encontrados nas condições reais de trabalho e estimula a participação ativa dos alunos na busca de soluções para os desafios. Em 2015, os encontros eram cinco vezes por semana, com quatro horas diárias. O perfil dos estudantes era o de jovens cursando o segundo ou terceiro ano do ensino médio ou que o haviam finalizado há menos de cinco anos. Tratam-se de jovens majoritariamente egressos de escolas da rede pública de São Paulo. A maior parte residia com os pais e seus gastos eram financiados pela família. De modo geral, escolheram o Curso Técnico de Design Gráfico por achar interessante e/ou por considerar o mercado de trabalho promissor, não por trabalharem na área, até por serem muito jovens, entre 16 e 22 anos, em sua maioria.

\section{Proposta de Reprojeto de Design de Embalagem}

A disciplina "Programação Visual de Design Promocional e de Marketing Direto", correspondente ao quarto módulo do Curso, por demandar conhecimentos e habilidades mais avançadas de design gráfico, foi realizada no último período da grade curricular, com duração de 190 horas, havendo sido ministrada por um único professor. Esta disciplina foi dividida em duas fases: a primeira visava a construção de conhecimento básico do design de embalagem para o desenvolvimento de competências, alternando aulas teóricas e exercícios práticos, que subsidiaria a elaboração do projeto final, em uma segunda fase. Aspectos teóricos abordaram componentes históricos, tipos de embalagem, conceitos compositivos, linguagem das formas e das cores, além de metodologia de projeto de design de embalagem. Desde o princípio, foi proposto aos alunos coletar embalagens para compor um repertório de alternativas existentes, posteriormente usadas 
para análises gráficas e de processos de impressão. Além disto, pesquisaram, na internet, leis e normas que incidiam sobre rótulos de embalagens alimentícias e de higiene pessoal. Executaram planificações, desenhos de faca de corte de cartonados e representações tridimensionais de diversas embalagens em aplicativos de desenho vetorial e de manipulação de imagens.

Com base nestas atividades, passou-se à fase de desenvolvimento do projeto, elaborado individualmente, cuja proposta era o redesign de uma embalagem de papel cartonado de produtos comercializados em supermercados (de mercearia, bebida, higiene pessoal ou limpeza), apresentando layouts e arte da faca de corte, bem como produção de peças gráficas para promoção do produto no ponto de venda. Para isto, o projeto foi dividido em quatro etapas: Planejamento, Forma, Entrega e Apresentação. A etapa "Planejamento" compreendia definir o problema do produto e peças para ponto de venda, pesquisar a concorrência do produto nos supermercados, analisar características gráficas do projeto da embalagem, elaborar documento de texto com justificativas, conceito, formato, identidade visual, paleta de cores e tipografia das peças. Quanto à embalagem, os alunos poderiam realizar pequenos ajustes dimensionais, sem, contudo, interferir significativamente no partido formal geral da embalagem, uma vez que a proposta era trabalhar, sobretudo, no âmbito da comunicação visual. Na etapa "Forma", deveriam produzir layouts e artes finais dos elementos visuais da embalagem e das peças promocionais, com formato compatível para impressão gráfica, seguida das etapas "Entrega" e "Apresentação".

\subsection{Embalagens para o Estudo}

Dentre os 21 projetos de embalagens apresentados, três trabalhos, considerados mais completos em termos da gama de recursos linguísticos do design, foram selecionados para este estudo, são eles: suco néctar Dafruta, água de coco Sococo e Linea Sucralose adoçante em pó. Os parâmetros utilizados para análise compreendiam: critérios para escolha da embalagem, relação entre elementos gráficos, cor, imagens, texturas, tipografia, logotipo, formato e aspectos semânticos. Vale lembrar que os apontamentos tiveram como base relatórios dos próprios alunos.

\subsubsection{Suco Néctar DaFruta}

No redesign da embalagem de suco néctar e do logotipo da empresa DaFruta (Figura 1), adotou-se como principais conceitos a leveza, simplicidade, funcionalidade e harmonia. Com base

Figura 1 - À esquerda, embalagem original; à direita, embalagem reprojetada do suco néctar DaFruta

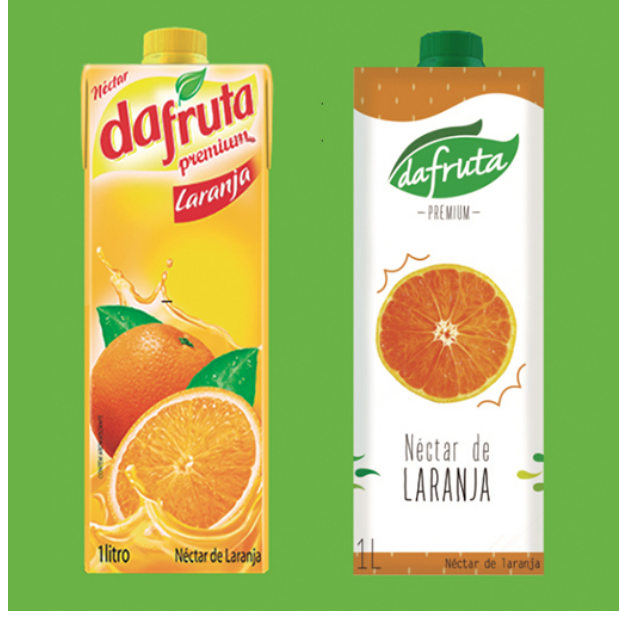

Fonte: criação do aluno 1 (2015) 
na flora natural, estabeleceu-se os elementos gráficos, texturas e cores. A este respeito, é notável que a imagem de "flora natural" houvesse sido espontaneamente evocada pelo próprio aluno. Em relação ao logotipo, notou-se grande alteração de aspecto original, com a utilização de cores quentes e excesso de elementos para um logotipo simples, objetivo e harmonioso, com cores que referenciassem à natureza, ícone em forma de folha e tipografia suave, que possibilitassem aproximação ao conceito estabelecido pelo próprio nome da empresa, "DaFruta".

\subsection{2 Água de Coco Sococo}

Com o redesign da água de coco Sococo (Figura 2) propunha-se diferenciar a embalagem nas prateleiras. Para isto, a imagem comumente empregada do coco caindo na água foi substituída por ilustrações que representassem praia, cenário em que a água de coco é mais popularmente conhecida, de forma limpa e simples. O formato vertical foi mantido, por ser o padrão de uma caixa de um litro da Tetra Pak. O logotipo não foi alterado para manter a identificação com o consumidor, porém a especificação do tipo de produto foi personalizada e destacada para melhor visualização. Foram escolhidas cores orgânicas que transmitissem leveza, naturalidade, alegria, saúde e diversão. O fundo acromático destacaria os elementos, atingindo o objetivo do redesign. Buscando valorizar a naturalidade, empregou-se tipos semelhantes aos feitos à mão, tanto para especificação do produto "água de coco", quanto para as informações do mesmo (quantidade, dados complementares etc.). Para demais dados, como tabela nutricional, ingredientes e endereço, empregou-se fontes simples, sem serifa, para acompanhar o layout.

Figura 2 - À esquerda, embalagem original; à direita, embalagem reprojetada da água de coco Sococo

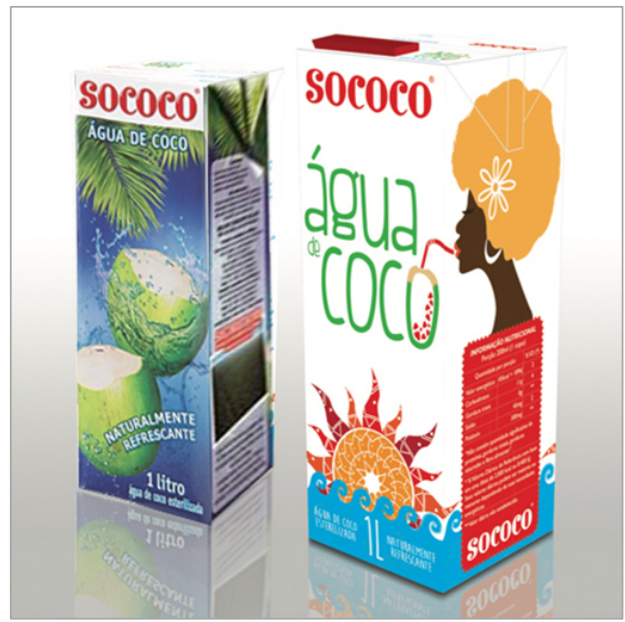

Fonte: criação do aluno 2 (2015)

\subsubsection{Linea Sucralose Adoçante em Pó}

A escolha do produto Linea Sucralose adoçante em pó (Figura 3) deveu-se ao excesso de elementos gráficos e de cores desconexas da imagem de fundo que não passavam o ideal da empresa, além de remeter a um público infantil. Com o redesign da embalagem, tencionava-se transmitir a qualidade do produto e a imagem de saúde e bem-estar para a embalagem, visando favorecer a assimilação com o produto e incrementar a aproximação com seu público-alvo. Para isto, utilizou-se uma comunicação mais simples, instantânea e sintetizada, por meio de cores já presentes, que mantivesse a familiaridade. Apenas o logotipo foi modificado, ficando mais plano. 
Além disto, foi escolhido um símbolo que definisse o produto e a empresa e que trabalhasse para criar uma nova comunicação visual para ambos. A profundidade na embalagem antiga, com elementos sobrepostos, deixou de ser percebida, permanecendo todos no mesmo plano, mas preservando o constraste alto, com todos elementos em destaque. O formato original foi mantido, bem como a tipografia, tipo simples sem serifa, por se adequar à proposta do novo layout.

Figura 3 - À esquerda, embalagem original; à direita, embalagem reprojetada de adoçante em pó Linea Sucralose

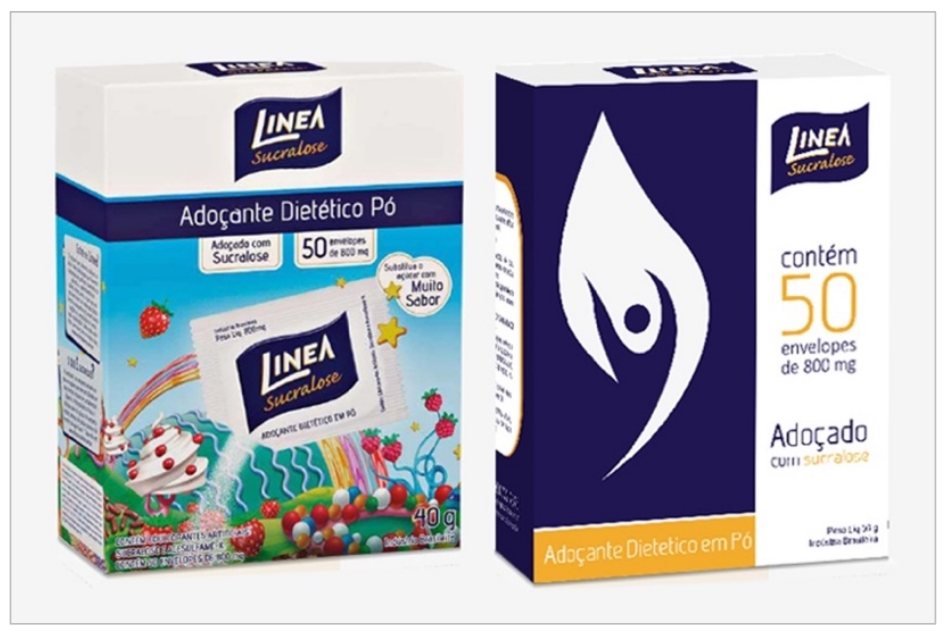

Fonte: criação do aluno 3 (2015)

\subsubsection{Sínteses}

Verificou-se, com estas três análises, maior atenção em justificar a escolha da embalagem para o redesign em relação aos demais alunos da classe. Enquanto o aluno 2 focou em diferenciar o produto em relação à concorrência, o aluno 3 enfatizou como problemática a grande quantidade de elementos não conectados na embalagem e provável não identificação de seu público-alvo. Já o aluno 1, abordou a necessidade de redesign também do logotipo do produto. Assim, o processo de criação pode fluir, partindo de desenhos, no papel, em busca de elementos gráficos e soluções compositivas, seguidas de pesquisas em livros e na internet, de imagens, cores, tipografia, entre outras, e posterior estudo em aplicativos gráficos.

Como resultado, nestes três casos, a tipografia utilizada era simples, sem serifa. A paleta de cores, enxuta. As imagens, sintetizadas. $O$ aluno 1 se dedicou ao redesign do logotipo e definição de elementos compositivos, o aluno 2 na elaboração das imagens vetoriais e no redesign da especificação do tipo de produto e o aluno 3 na definição de um símbolo que representasse tanto o produto quanto a empresa. Os três alunos se atentaram para a relação entre os elementos, chegando a soluções de design distintas.

\subsection{Análise com Base em Lupton e Phillips e também em Bonsiepe}

As três embalagens resultantes desta experiência de redesign, a partir de Lupton e Phillips (2008), tiveram como parâmetros para análise formal: ritmo e equilíbrio, escala, textura, cor, enquadramento, hierarquia, tempo e movimento, entre outros. Para Bonsiepe (2011), em vista da grande quantidade de mensagens verbais e visuais produzidas e distribuídas pelas sociedades industriais, o uso de instrumentos retóricos possibilita incrementar a compreensão das informações. É notável que, frequentemente, vários "patterns" atuam em conjunto. 


\subsubsection{Suco Néctar DaFruta}

Com o redesign da embalagem de suco néctar DaFruta (Figura 4), o uso da forma básica e estável da imagem da laranja, com cores de valores contrastantes, propiciou tanto enfatizar como contrabalancear o peso da cor e da forma mais dinâmica do logotipo e a leveza da tipografia (com a designação do sabor do suco). No que se refere à parte superior das vistas frontal, posterior e lateral da embalagem, os elementos de funcionalidade promoveram um padrão de continuidade entre itens independentes, configurando-se uma ideia de sistema, por exemplo, na sequência do fluxo da faixa ondulante, que é preservada no meio a várias embalagens dispostas lado a lado. De modo similar, o agrupamento dos elementos em forma de gota (com cores verdes adjacentes, formado pela proximidade) promoveram ritmo e contiguidade, além de enquadrar a designação do sabor do suco. O enquadramento também foi estabelecido pelos elementos gráficos que envolvem a imagem da fruta. Estando os elementos distribuídos de maneira harmônica em cada uma das faces, a embalagem transmite equilíbrio visual, no caso, axial simétrico.

Em se tratando dos "patterns" visuais-verbais, identificou-se o "pattern sinédoque", em que uma parte representa o todo: a folha como "sinédoque" de fruta. Além disto, está presente o "pattern especificação", uma vez que o sinal visual (imagem da laranja) é acompanhado de um mínimo de texto (néctar de laranja), conferindo-lhe maior precisão semântica.

Figura 4 - Representação tridimensional das embalagens reprojetadas de suco néctar DaFruta dispostas lado a lado

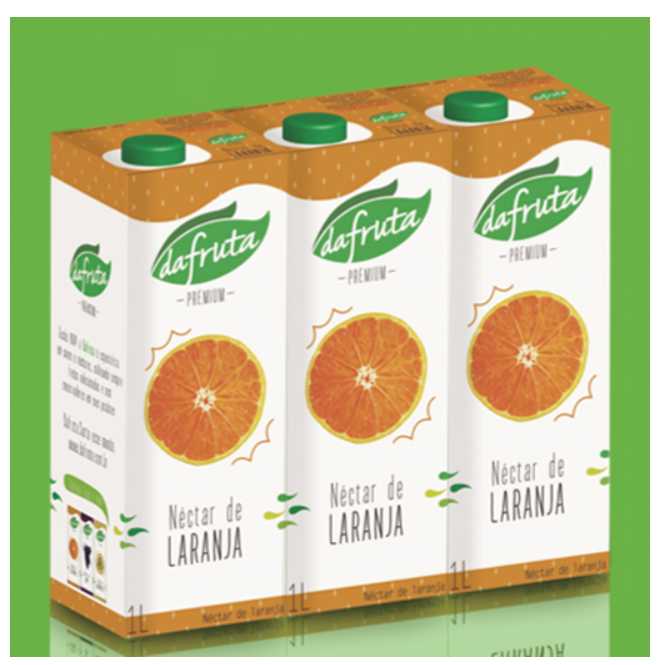

Fonte: criação do aluno 1 (2015)

\subsection{2 Água de Coco Sococo}

Conforme Lupton e Phillips (2015), a hierarquia visual controla a transmissão e impacto da imagem. O olhar vai para a figura do sol, com suas cores quentes, contrastando com a cor fria do mar, que, por sua vez, transmite a sensação de ritmo e continuidade, por meio das curvas das ondas ao circundar todos os planos (Figura 5). A cor dos raios de sol, que remete ao logotipo da empresa, possibilita a identificação do consumidor. Assim como na embalagem anterior, imagens, logotipos e tipografias apresentam-se distribuídos, em cada face, em equilíbrio axial simétrico.

Quanto aos "patterns" visuais-verbais, constatou-se o "pattern tipograma", em que o significado das letras tipográficas (água de coco) é percebido por intermédio da visualização das 
próprias letras (ilustração do coco na última letra "o"). Além disto, está presente o "pattern transferência visual-verbal", em que a palavra "água de coco" é associada à praia por meio de imagens de sol e mar.

Figura 5 - Representação tridimensional da embalagem reprojetada de água de coco Sococo

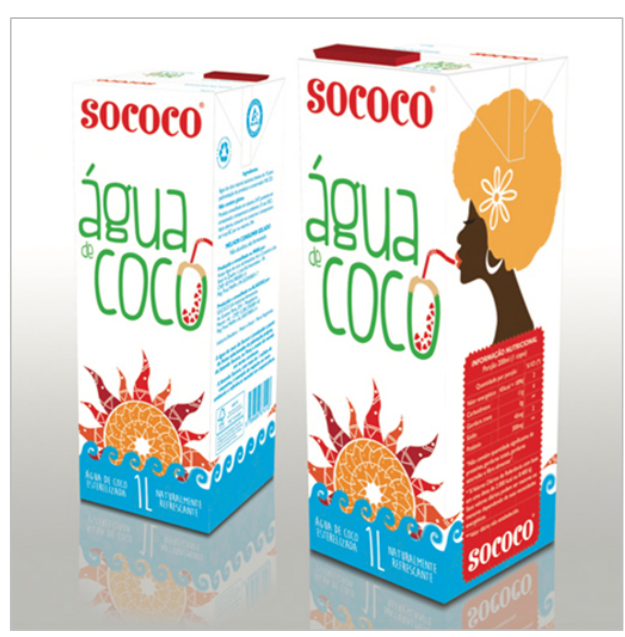

Fonte: criação do aluno 2 (2015)

\subsubsection{Linea Sucralose Adoçante em Pó}

Segundo Lupton e Phillips (2015, p. 99): “A criação de ambiguidade entre figura e fundo pode acrescentar energia visual e surpresa a uma imagem ou marca.", evidenciada no redesign da embalagem de adoçante em pó Linea Sucralose (Figura 6), realçada mediante a utilização de cores de valores contrastantes. A tipografia empregada no logotipo e demais especificações escritas, com mudanças de escala e de localização, contribuiu para exprimir seu significado em diferentes graus de importância. Este projeto, por ser assimétrico, mostrou-se mais ativo que os demais.

Figura 6 - Representação tridimensional da embalagem reprojetada de adoçante em pó Linea Sucralose

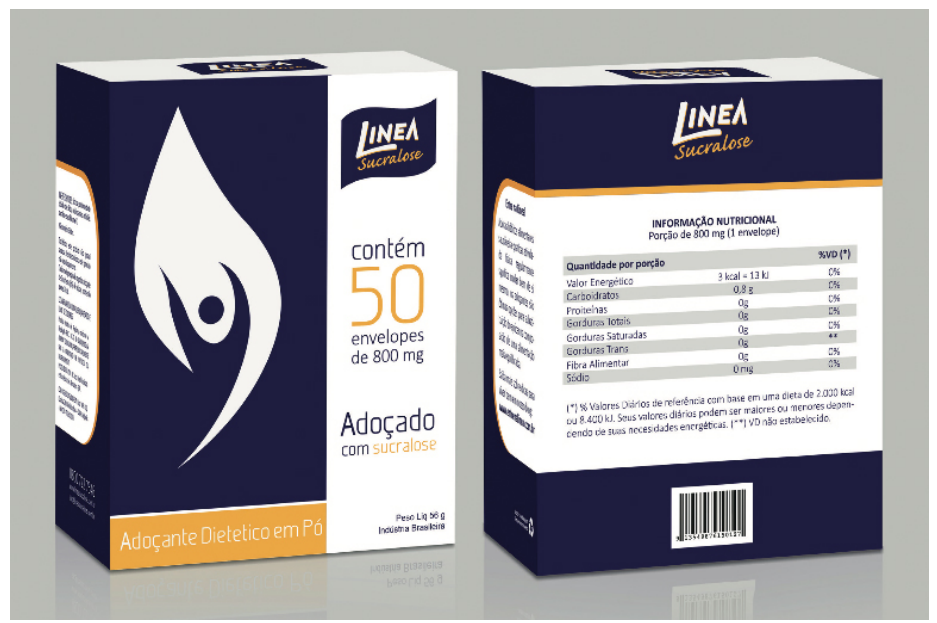

Fonte: criação do aluno 3 (2015) 
Em relação aos "patterns" visuais-verbais, evidenciou-se o "pattern analogia", mediante comparação verbal: o nome da empresa "Linea Sucralose" foi transferido ao campo visual por meio de sinais semânticos equivalentes (ilustração de pessoa magra, "na linha"). Além disto, percebeu-se o "pattern transferência visual-verbal", em que o texto "adoçante em pó" foi representado por uma pessoa dentro de uma gota, em contexto associativo ao uso mais comum: "adoçante em gotas".

\section{Resultados}

Dentre os trabalhos analisados, constatou-se preferência por formas simples, sintéticas e simplificadas. Não foram utilizados logotipos ou textos na diagonal, nem em sentido radial, que sugerissem movimento, mas soluções que transmitiam estabilidade. As tipografias adotadas eram simples, sem serifas e as cores, empregadas de maneira funcional, garantiram legibilidade.

A grande recorrência no uso de desenhos vetoriais nas imagens principais sugere preferência pelo aplicativo "Illustrator", seja em termos de habilidade ou da linguagem visual, propiciada por programas vetoriais.

Percebeu-se, ao final desta experiência pedagógica de projeto de design, significativo avanço na habilidade dos alunos em verbalizar a justificativa, o planejamento e o processo de estudo, em comparação aos relatórios de pesquisa executados em disciplinas iniciais do Curso, evidenciando a importância de se incentivar a capacidade de expressão verbal.

A dedicação, com maior afinco, à fase de planejamento, sobretudo na análise das características gráficas da embalagem escolhida para o reprojeto e dos produtos análogos da concorrência direta do produto no ponto de venda, parece haver contribuído para melhor entendimento do problema, facilitando as etapas subsequentes e sua resolução.

\section{Considerações Finais}

Em uma avaliação geral da experiência, foi perceptivo o envolvimento crítico e analítico dos alunos que participaram mais ativamente. Eles aparentaram, a seu final, estar mais atentos e capazes de articular observações críticas e a identificar relações associadas à classe de embalagens de produtos comerciais, parte bastante presente em suas vidas e na cultura material que os cerca. A experiência também parece haver estimulado, em vários alunos, interesse por design e por profissões em áreas afins.

A análise desta experiência de redesign de três embalagens não busca sua generalização, mas dar oportunidade de reflexão sobre a pedagogia do design para jovens desta perspectiva de resolução de problemas projetuais de design. Espera-se que jovens expostos a conteúdos, métodos e pensamento de design se tornem, complementarmente, mais aptos a aplicar alguns dos princípios de design exercitados tanto a outras áreas de conhecimento em que passem a atuar, quanto a suas vidas, como usuários e cidadãos.

\section{Referências}

BONSIEPE, G. Design, cultura e sociedade. 2.ed. São Paulo: Blücher, 2011.

BONSIEPE, G. Do material ao digital. São Paulo: Blücher, 2015.

BRASIL. Parecer CNE/CEB 16/99, de 5 de outubro de 1999 que estabelece as bases para a definição de Diretrizes Curriculares Nacionais para a Educação Profissional Técnica de Nível Médio. 
COSTIN, C. Ensino técnico e profissional no Brasil. In: Opinião-Estadão, 2015. (http://opiniao.estadao.com.br/noticias/geral,ensino-tecnico-e-profissional-nobrasil,10000003243).

FERRETTI. C. J. As escolas técnicas se salvaram. In: Difusão de Ideias, 2006. (http://www.fcc.org.br/conteudosespeciais/difusaoideias/pdf/entrevista_escolas_tecnicas.pdf).

FERRETTI. C. J. Formação profissional e reforma do ensino técnico no Brasil: Anos 90. (http://www.scielo.br/scielo.php?script=sci_arttext\&pid=S0101-73301997000200002).

LUPTON, E., PHILLIPS, J. C. Novos fundamentos do design. 2.ed. São Paulo: Cosac, 2008.

NEGRÃO, C., CAMARGO, E. Design de embalagem: do marketing à produção. São Paulo: Novatec, 2008.

SCACCHETTI, F. A. P. Motivação e uso de estratégias de aprendizagem no ensino técnico profissional. 2013, 117 f. Dissertação (Mestrado em Educação) - Universidade Estadual de Londrina, Centro de Educação, Comunicação e Artes, Londrina, 2013.

SENAC DN. Educação profissional técnica de nível médio: cenário e perspectivas. Rio de Janeiro: SENAC/DEP/CTP, 2007.

SENAC. Proposta pedagógica. (http://www.sp.senac.br/pdf/53727.pdf). 